clavicle, which pulsated and slowly increased in size. On admission, an aneurysm of the third and involving a portion of the second part of the subclavian artery was diagnosed. He was treated by rest, careful diet, and the iodide of potassium for about a month, with the result that his symatoms were relieved, but the aneurysm remained in much the same state. He then left the hospital at his own desire, and he promised to return if he became worse. Nothing more was heard of him until he was readmitted in May, 1885. His symptoms had again increased, and he complained much of a dull aching pain over the right side of his chest, and shooting towards his back. The aneurysm was the size of a small orange, and pulsated strongly ; a marked bruit was present. The tumour was situated immediately above the centre of the right clavicle, and the pulsation passed down into the axillary artery, which was somewhat dilated. The heart-sounds were normal, except that those over the aortic area were fainter than usual. The radial pulses showed signs of slight atheroma. The other internal organs were healthy. No history of syphilis could be obtained. On May 27th I exposed the innominate artery by the median cervical incision, and readily separated with my finger and a director the tissues, so as to allow the former to pass behind the artery and compress it against the sterno-clavicular articulation. The compressor was then applied, and found also to act in thoroughly staying all circulation in the ressel and its branches. The compressor having been removed, an indiarubber drainage-tube, with a diameter of half an inch, was inserted into the wound and adjusted so that its one extremity lay behind the artery and the other protruded from the external wound. The drainage-tube was secured in position by a piece of silk thread tied round the neck. The operation was performed with the usual antiseptic precautions, and the wound was dressed with salicylic wool applied loosely over it. On the 28th his temperature was $99.4^{\circ}$. The wound was dressed, and looked well. On the 29th he complained of pain in the wound, and had a slight dry cough. His temperature was $102^{\circ}$. On the 30 th his cough was better, and his temperature was $101 \cdot 2^{\circ}$. On the 31 st the wound was dressed for the second time since the operation. It had in great part healed, except at the point of insertion of the drainage-tube. The tube was removed, cleaned, and replaced. Cough still troubled him. After this date the patient's progress was most favourable, and the wound was dressed daily; it remained aseptic. On June 6 th it was noted that the cough had entirely disappeared and the patient was otherwise well. He still complained of some pain in the lower part of the neck. On the 7 th there was a small quantity of blood upon the dressings, but nothing to cause any alarm. On the 8th, while the patient was sitting up in bed, serious arterial hæmmorrhage suddenly took place, which was temporarily checked by passing the finger deeply into the wound and compressing the artery against the sternum. Shortly afterwards I visited him, and finding that the bleeding proceeded from a point in the innominate artery, I prolonged the original incision along the line of the elavicle so as to expose the artery more thoroughly and apply a ligature round it. As I required to keep the finger of one hand upon the bleeding point, I found it impossible to pass a ligature round the vessel between the heart and this finger, although I made several attempts to do so. I then applied the compressor in the way described, and this completely stayed the bleeding. By this time the patient was almost pulseless, and, although no furtherbleeding took place, he sank and died about five hours after. The post-mortem examination disclosed an aneurysm about the size of a hen's egg involving a small portion of the second and the whole third portion of the subclavian artery. The axillary artery was also dilated, especially in the first part of its course. At a point on the posterior aspect of the innominate artery, and immediately below its bifurcation, there was an oblique slit or ulceration nearly a quarter of an inch in length involving its entire coats ; the other portions of the artery and the heart and aorta were in good condition, and did not show any marked traces of atheroma. The ulceration in the coats of the artery exactly corresponded to the point against which the drainage-tube rested, and there were two small spots on the trachea which showed signs of commencing absorption, the result of the pressure of the same tube.

In connexion with this case I would remark, first, upon the cause of the fatal secondary hæmorrhage; and, secondly, upon the future prospects of compression of the innominate artery for the relief of aneurysms on the right side of the neck.
1. The cause of the fatal hømorrhage was, in my opinion, the ulceration of the coats of the artery owing to the continuous pressure of the drainage-tube. I am not aware that the pressure of a drainage-tube has been thought likely to lead to so serious a result as in the present case, more par ticularly when the wound in which it lay remained aseptic but from the experience of this case and of others of which I have quite recently heard, I consider that we must now reckon this risk as possible and avoid any lengthened continuous pressure upon a large bloodvessel by a drainagetube. It may be said that the manipulation of the artery when the drainage-tube was first introduced may have assisted in destroying or weakening the coats of the artery, but as the artery was in a healthy condition and the manipulations of it were conducted with gentleness, I do not think so, and would attribute the rupture entirely to the results of the pressure of the drainage-tube.

2. Owing, then, to the unexpected accident caused by the drainage-tube, my proposed suggestions for the treatment of this case could not be carried out; nor do I adrise that they should in any future case be employed exactly upon the same lines. I do, however, still hope that by some modification of the compression of the innominate we may succeed in relieving aneurysms which admit of no treatment other than the unsatisfactory one of ligaturing this artery. The direction of this modified compression should, I venture to assert, be on the principle of applying, with the assistance of a central cervical incision, digital or instrumental compression to the innominate artery, the patient being under the influence of some anæsthetic. Such compression should not be too continuous, and should be combined with distal ligature or compression, or, if thought advisable, with electrolysis.

\section{THE EARLY TREATMENT OF RHEUMATOID ARTHRITIS.}

BY JOHN KENT SPENDER, M.D. LoND., PHYSICIAY TO THE MINERAL WATER HOSPITAL, BATE. (Concluded from p. 441.)

THE subject of Treatment is bright or dark according to circumstances-very bright if we have faith in our work, if the disease be in an early stage, and if we will take endless trouble to prevent a small spark from becoming an unmanageable flame. The therapeutics of rheumatoid arthritis is encouraging if we rightly estimate the proportion of general and local treatment, if the social and hygienic surroundings of a patient be favourable, and if we can secure the help of intelligent relatives and sensible nurses. When the nature of a case is clear, and the gravity of the coming evil plainly seen, it is downright treason to hide or to minimise it. Our duty is to be truthful, and at the same time it is a privilege to be hopeful ; and in this spirit we shall best undertake what we are going to do.

Local treatment I put without hesitation in the foreground. By this is meant, not that in the long run the local treatment is the more important, but that we ought to begin with it, because time is urgent, and because in this manner we can make the earliest and deepest impression. Here is something wrong (call it what we will) in structures near the surface of the body ; it is reasonable, it is almost certain, that we shall first influence this evil tendency by corrective discipline applied closely to the parts affected. It is easy to write with an air of learning about counter-irritation, although we know little about it as a theory; but there can be no doubt of its power as a piece of therapentic work. Almost alone among recent writers has Dr. Mitchell Bruce advocated the necessity of vigorously striking home on the joints themselves. " It is satisfactory to quote a good authority in favour of a practice which I have followed for ten or twelve years. But the laws and limits of counterirritation must be stringently observed. To put a cantharides blister all over a joint, or to paint the whole exterior of a joint with liniment of iodine, is to commit a grave therapeutic blunder. The antipathies of resentment are stirred in the vaso-mutor apparatus under the skin, and the immediate

1 Quain's Dictionary of Medicine. But it must be admitted that Dr. Bruce's opinions of the pathogeny of rheumatoid arthritis are contrary to established doctrine. 
harm overshadows all possible future good. Mr. Furneaux Jordan's rule is plain and wholesome physiology. "Put, your irritating agent," he says, "on the circumjacent skin, or, in other words, the neighbouring nerve and vascular territory." The artificial hyperæmia thus created draws away perverted force from the diseased area, and helps to restore an equilibrium. Paint a ring of linimentum iodi around the lower part of a thigh, two fingers' breadth away from a threatening 'rheumatoid' knee; let the ring be one inch and a half wide; renew it every two or three days, according to the coarseness or delicacy of the skin. Puint a similar ring below the knee, renewing it, not at the same time, but alternately with the ring above. If a cantharides blister be applied, let it be always on the cardiac side of a joint; and the blistered surface should be allowed to heal immediately. Another excellent method of counterirritation is the frequent sponging of the affected joints in the earliest stage with water as hot as can be borne, the calorifacient edge of the heat being blunted by covering a joint with flannel or layers of muslin.

Many are the fine degrees and finer shades of what we call counter-irritation, and the method of using it should be always of the slow and quiet kind. Turpentine and its congeners are incendiary drugs, kindling a rapid fire which can be seldom kept within modest bounds. But there is a more generalised and tranquil method of so-called counter-irritation, which consists of immersing the whole body in hot or tepid water. The Bath thermal waters owe much of their repute to the well-attested faculty of alleviating the medical group of joint disorders, known as rheumatic, gouty, and osteo-arthritic. There is something in natural thermal water which confers upon it unique therapeutic power; for when stripped of the accessories of change of air and scene, of recreation and rest, a residual virtue is discovered which baffles the most searching inquisition. Thermal medicine is a matter of experience and tact; but this point stands out beyond all cavil, that the machinery of thermal bathing is successful in exact proportion to its early use. When proper means have been neglected at the proper time, then that stupid hope which leans upon anything will build castles in the air, and imagine a natural magic in ores, herbs, and waters. From this indolent delay there is often a cruel awakening. But if the regimen of a thermal spa be accepted and obeyed when a rheumatoid arthritis is in its dawn, if the twilight beginnings of a destructive disease are grappled with bit by bit, and hands are joined all round to beat back the foe, we may sometimes win the day when we least expect it, and add laurels to the honourable warfare of medical art.

Douching and shampooing are therapeutic kinsfolk to bathing, and (as a rule) all should go together. "Wet douching" is preferable when joints are sensitive and muscular action is attended by labour and pain. But for rousing structures out of drowsiness, and for stimulating them when afflicted with vital apathy, few agencies are so useful as "dry" hot and warm douches (the body being out of water). The thermal arrangements in Bath have been lately much improved; and a room has been attached to the "Queen's Baths" in which all the best appliances of Aix-lesBains can be enjoyed, with foreign doucheurs and doucheuses. Shampooing is a technical mystery which cannot be too highly praised. The younger the patient who is menaced with rheumatoid arthritis, the more important does it seem to carry out stroking (effleurage) of the joints and tender kneading (petrissage) of the neighbouring muscles. The limbs should be always in the least constrained posture, and the application of bandages and laced supports will test the surgical instinct of the "wise physician." It cannot be said that the external use of drugs does any good; but I have been long accustomed to order the mild inunction every night of the iodide of potassium and soap liniment.

Climate is an element of soothing and healing value. To avoid the English winter and spring sounds disloyal; but to those who can afford it the sacrifice is imperative, and aliens they must be for six or seven months in the year. Between November and May residence should be taken up on the Mediterranean sea-coast, or part of the time may be spend in a sub-tropical sea voyage. This may need to be repeated every year for several years before complete success is obtained. Rheumatoid arthritis is a disease par excellence of the north temperate zone. But as the vast majority of people can only dream of the Mediterranean and the luxuries of Algiers and Egypt, they must learn to do the best for themselves in their own country, and to live in a dry and not too cold part of England; out of the "search of the glacier wind," says Mr. Ruskin, and as much as possible in the "rays of the rare sunshine." Internal medicines capable of doing good may be divided into two classes:(a) Those of unquestioned efficacy, because of their obvious physiological appropriateness; and (b) those of secondary utility, but helpful according to their mode and measure of administration. In the front rank of the first class stands cod-liver oil, food and physic together; if begun in small quantities with pancreatine or orange wine, it may be pushed discreetly until half a pint is consumed every week. This must be continued for months, perhaps for years, omitting the middle of the summer; and it is a merciful plan to allow a holiday from all drugs once a fortnight. Citrate of iron (five or six grains) and iodide of sodium (two or three grains) may be dissolved and given together in chloroform-water once a day. Among our pharmaceutical resources of lesser importance are strychnia, arsenic, and syrup of the iodide of iron. When arsenic agrees, it may rise to the dignity of a valuable medicine, and there is no reason why it may not be given with the iron and cod-liver oil. Syrup of iodide of iron has been extolled by several writers, and is certainly a model of quiet harmlessness.

Countless hygienic rules may be laid down, and it will be a happy chance if our patient obeys half of them. Rooms well ventilated night and day; the steady morning and afternoon trudge out of doors, to keep muscles and joints from stagnation, and to promote the "metabolism" of effete stuff from the body; plenty of sun and sea; clothing adapted to the ever-shifting stress of weather; and meals of varied and well-cooked food. And if the mind and the affections be rightly guided wat more can we do? In short, what we call the prophylaxis of cerebral and pulmonary consumption is the most rational way of warding off the diathetic state which leads to rheumatoid arthritis. The victories of preventive medicine have only begun to be unfolded. ${ }^{2}$ When the hands and feet are the members first attacked, and the fingers are early disabled by pain and swelling in the smaller joints, the regular application of galvanic electricity may be tried. I cannot say much in its praise, and the therapeutic uncertainty of electricity has now become almost a proverb.

From an abundance of clinical material I select a case which is interesting, because it shows what can be done when there is a determination all round to do the very best. In April, 18s1, Sir Andrew Clark kindly entrusted to my care a young lady, aged seventeen, the daughter of a gentleman (a most munificent churchman) residing in the north of England. During 1879 she suffered much from chronic ulceration of the throat, and was obliged to leare school in March, 1880, "weak, white, and tired." The hands began to swell, and then the feet; many spas were visited during this summer for the benefit of her health; but in February, 1881 (after a severe winter), she became gradually worse and pain and stiffness began to be felt in the left thigh and both shoulders. When she came to Bath she had great difficulty in raising herself from a chair, and walked with a stoop forwards; the muscles of the limbs were flabby from want of use; but there was no emaciation, and her manner and general tone were full of sprightliness and animation. The medical history of the family was good, with a marked exemption from rheumatic troubles. Many details are omitted for the sake of brevity; and it will suffice to say that a course of six weeks' thermal bathing here, followed by a similar period of perfect rest at Buxton, seemed to give the first impulse to that convalescence which was all the more firm and real because it was spread over several years. Every winter and early spring were spent at San Remo or at Cannes; sometimes there was a short visit to Aix-les-Bains; and four or five of the summer and autumn months were spent in England. Skillful shampooing was constantly used, and cod-liver oil was taken with as much regularity as possible. I heard from my patient once or twice every year; and in the last

2 Horace tells Mrecenas that if he would live sound and in perfect health, the same indulgence which was granted to him when ill must be granted when he was afraid of bcing ill :-

"Si me vivere vis sanum rectèque valentem.

Quam mihi das ægro, dabis ægrotare timenti,

Mrecenas, veniam."-EPrsT., lib. $\dot{i}_{\text {, }}$,

3 In a paper read (June, 1880) to a Yorkshire branch of the Britisl Medical Association by Dr. Little of Ben Rhydding, three cases are related of successful treatment, by electricity, shampooing, and Russian baths. In the early stage of rhenmatoid arthritis, however, Turkish baths and chamber vapour baths only weaken the patient without arresting the disease. 
letter (from Cannes, dated Dec. 22nd, 1884) she says: "I have been so well this year. I am much stronger and better this year than last; I can walk much quicker, and have much more use of my hands. My weight also has largely increased." Now this patient might have been easily given up as hopeless; nor would there have been any ground for hope if she had been one of the crowd of those sufferers who are exposed to the chances of weather and porerty and mental depression. In these the little store of nerve force is exhausted by the physiological maintenance of common life. There is no reserve, no hidden power equal to the fervour and passion of driving out of the system a retrogressive change. There may be an amelioration of health, but the "supple government" of the joints can never be renewed.

In divers ways I have now endeavoured to show the "grief and gravity" of a terrible disease; to be a friendly monitor of its sure ending if unchecked, and to give a hopeful tone to our prognosis when opportune events put us in command of the whole line of treatment. In few diseases is time so irrevocable. Our pity should be aroused when belolding the monumental effigies of once bright and actire men and women, now laid on sofas or Ilkley couches, and dependent for the humblest office on the ministry of others. The Laureate cheerily sings-

$$
\begin{aligned}
& \text { Oh ! well for him whose will is strong, } \\
& \text { He suffers, but he will not suffer long." }
\end{aligned}
$$

Bit our dirge is of those who are doomed to suffer long, notwithstanding the comfort of a "strong will" and a supernatural grace. The corporate conscience of the whole profession ought to be stirred in this matter, for it is a reproach to medical art if any curable disease be let run into an incurable form. Dynamic disturbances, which may be easily plucked out in the early blossom, become anarchic and rebellious in their time of fruit. To wait for "specific" remedies or to trust to random discoveries is idle play and not scientific medicine. I venture to express the opinion that the proper treatment of rheumatoid arthritis consists in seizing the right threads at the very beginning, and in holding them with a fighting purpose to the very end. And it will be a natural conclusion to my argument if I suggest that the means be always precisely adapted to our aims, measuring the one with the other under the varying circumstances of race, sex, temperament, and age.

Bath.

\section{SPASTIC PARALYSTS.?}

\section{BY A. HUGHES BENNETT, M.D., F.R.C.P.}

Mr. Prestdent,-At your invitation I attempt to bring before the Society a subject of great importance. It concerns a morbid state of widely-spread occurrence, and one which must therefore frequently come under the notice of every medical man. It is, notwithstanding, a condition very obscure in nature, causation, prognosis, and treatment. In consenting to open a conference on spastic paralysis, I do not anticipate that the darkness which surrounds the question will be illuminated by any original revelations of $\mathrm{my}$ own. I am, however, encouraged to venture the undertaking by the belief that directing attention to the leading problems to be solved will, without effort on my part, supply a text which the learned may expound, and thus initiate a discussion which may prove of scientific and practical value.

Spastic or spasmodic paralysis is the name which has been given by Professors Erb and Charcot, not to a disease, but to a group of symptoms-to a clinical picture-which must be familiar to everyone. It essentially consists of a morbid condition in which motor weakness, exaggeration of the tendon phenomena, and rigidity of muscles are the prominent and characteristic features. Owing to the existence of these physical states the patient afflicted suffers from certain symptoms which as a consequence ensue-namely, deficient voluntary activity, tremors, peculiarities in gait, and distortions of the limbs. This combination of circumstances is, moreover, not of necessity associated with any

1 An introduction to a discussion on the subject at the Medical Society of London, March 1st, 1866. interference with the general health or the functions of the body, and the intellectual, sensory, and nutritive organs may be preserved intact. In short, this train of abnormal symptoms, to which the term "spastic" has been applied (owing to muscular spasm being the leading feature of the disorder), is strictly contined to the motor elements of the nervous system.

The distribution of this spastic condition varies. It may be confined to a single limb, it may assume a hemiplegic or a paraplegic form, or it may involve all four extremities and every district of the body. As regards causation, it may be associated with degeneration of the lateral columns of the cord, secondary to disease of the brain or pyramidal tract, as in cerebral hremorrhage, myelitis, \&c.; or the lesion may be of primary origin in the same regions, thus constituting a disease per se, as in so-called primary lateral sclerosis. Also it is met with as a functional disorder from unknown causes, as in hysteria; and it may be the resuit of certain definite blood-poisons, such as strychnia and lathyrus cicera. Further, as to pathology, it is frequently accompanied with demonstrable structural alteration in the nervous system, which appears to be its direct cause, and as often all traces of discoverable tissue change are absent. Again, the progress of the disorder is not uniform: at one time it invades rapidly, is acute, and of short duration; and at another is insidious in origin, chronic, and of long persistence. Finally, its termination varies, in some instances the disease being hopelessly and permanently incurable, while in others the patient rapidly and completely recovers. This varied distribution, origin, pathology, progress, and termination of the same group of symptoms furnishes a mystery to unravel, and serves to show how perplexing are the difficulties of the subject under notice.

Various theories have been propounded to explain the occurrence of spastic paralysis, the essential features of which, it may be repeated, are motor weakness, exaggeration of the tendon phenomena, and muscular rigidity. Professor Charcot maintains that the symptoms are due to irritation of the ganglion cells of the grey matter of the cord by degenerated contiguous fibres of the lateral columns. It is now well known that a destructive lesion of the motor cortical area in the cerebral hemispheres, or in any portion of the pyramidal tract, induces secondary degeneration of the efferent fibres below, which are thus cut off from the trophic influences of the cells in the grey matter of the brain. This sclerosis extends downwards as far as the multipolar ganglia in the anterior cornua of the cord, and the hypothesis suggested is that the morbid process on reaching the cells causes their irritation, and as a consequence the phenomena of spastic paralysis. That this theory is plausible cannot be denied, and it is possible that it may be a factor in the production of the clinical symptoms in question. It is at best, however, only an imperfect explanation, and not the essential cause, as spastic paralysis may exist in its most typical form when no degeneration of nerve fibres can be demonstrated, as in various functional complaints such as hysteria. Moreover, it may occur under circumstances where it is impossible to conceive the presence of any such permanent or gross structural alteration, as in strychnine poisoning or during the hypnotic state.

Another theory, and perhaps the most popular, asserts that the symptoms of spastic paralysis are due to the simple severance of the spinal from the cerebral centres. In this way it is supposed the inhibitory action of the higher is removed from the lower ganglia. These last are, as it were, thus permitted, from want of control, to run riot, and as a consequence to manifest hyper-excitability of reflex acts, in the shape of increased tendon phenomena and muscular rigidity. It is admitted that during the absence of brain influences the reflex excitability of the cord is augmented, but the train of symptoms included under the term spastic are not produced. Moreover, in sudden destructive lesions of the brain, such as bæmorrhage into the pyramidal tract, although spastic symptoms subsequently ensue, they do not appear until a considerable period of time has elapsed. Now, if simple inhibition were the sole cause of the phenomena, we should expect the effects to be most marked at the moment of interruption, and not gradually acquired, as is the case.

A third theory, which is a modification of the last, maintains that when cerebral influences are suppressed the uncontrolled action of the cerebellum as a stimulator of muscular tonus becomes prominen ${ }^{+}$, and hence the stiffness which takes place. The same arguments which can be 